\title{
O ENSINO DE LÍNGUA PORTUGUESA PARA ESTRANGEIROS: IMPLICAÇÕES DA PLURALIDADE DE CONCEITOS
}

\author{
ENSEÑANZA DE LENGUA PORTUGUESA PARA EXTRANJEROS: IMPLICACIONES \\ DE LA PLURALIDAD DE CONCEPTOS
}

\author{
TEACHING OF PORTUGUESE LANGUAGE FOR FOREIGNERS: IMPLICATIONS \\ OF THE PLURALITY OF CONCEPTS
}

\author{
José Genival Bezerra FERREIRA ${ }^{1}$
}

RESUMO: O artigo apresenta os resultados preliminares do pós-doutoramento na Faculdade de Educação da Universidade de São Paulo. Discute as terminologias utilizadas pelas universidades para denominar a disciplina Português Língua Estrangeira - PLE. Como sabemos, essa disciplina pode ser designada de língua adicional, língua de herança, língua de acolhimento, entre outras. Nesse particular, a investigação busca entender se há razões para a existência de tantas denominações. Nesse sentido, faz-se necessário pesquisar se as nomenclaturas têm abordagens e/ou metodologias diferentes, com vistas a entender a opção por adotá-las. Para tanto, aplicamos um questionário, por meio do Google Forms, a professores que trabalham com o PLE em diversas instituições universitárias, para conhecermos suas percepções sobre a temática. Os resultados demonstram que, na prática, a maioria dos docentes não fazem diferença entre Português Língua Materna - PLM e PLE quanto às abordagens de ensino, bem como desconhecem particularidades das várias concepções existentes.

PALAVRAS-CHAVE: Português Língua Estrangeira. Ensino. Pluralidade de conceitos.

RESUMEN: El artículo presenta los resultados preliminares de un posdoctorado en la Facultad de Educación da Universidade de São Paulo. Se analiza la terminología utilizada por las universidades para denominar la disciplina Portugués como Lengua Extranjera PLE. Como sabemos, esta asignatura se puede denominar lengua adicional, lengua de herencia, lengua de "acolhimento" (acogida), entre otras. Al respecto, la investigación busca comprender si existen razones para la existencia de tantas denominaciones. En este sentido, es necesario investigar si las nomenclaturas tienen diferentes enfoques y / o metodologías, con miras a entender la opción de adoptarlas. Para esto, aplicamos un cuestionario, a través de Google Forms, a los profesores que trabajan con el PLE en varias instituciones universitarias, con el fin de conocer sus percepciones sobre el tema. Los resultados muestran que, en la práctica, la mayoría de los profesores no distinguen entre Portugués Lengua Materna - PLM y PLE en cuanto a enfoques de enseñanza. Además, desconocen las particularidades de las distintas concepciones existentes.

PALABRAS CLAVE: Portugués como Lengua Extranjera. Enseñanza. Pluralidad de conceptos.

${ }^{1}$ Universidad de Santiago de Chile, (USACH), Santiago - Chile. Professor Associado no Departamento de Linguística e Literatura. ORCID: https://orcid.org/0000-0002-5419-7449. E-mail: jose.ferreira@usach.cl 
ABSTRACT: The article presents preliminary results of a post-doctorate program at the Faculty of Education at the Universidade de São Paulo. It discusses the terminology used by universities to name the discipline Portuguese as a Foreign Language. As we know, this subject can be called additional language, heritage language, host language, among others. In this regard, the investigation seeks to understand whether there are reasons for the existence of so many denominations. In this sense, it is necessary to research whether the nomenclatures have different approaches and/or methodologies, to further understand the option to adopt them. For that, we applied a questionnaire, through Google Forms, to professors who work with the PLE in several university institutions, in order to know their perceptions about the subject. The results show that, in practice, most teachers do not make a difference between Portuguese Mother Tongue and Portuguese as a Foreign Language in terms of teaching approaches and are unaware of the particularities of the various existing conceptions.

KEYWORDS: Portuguese as Foreign Language. Teaching. Plurality of concepts.

\section{Introdução}

O presente estudo dialoga com o projeto Imagens da língua: sujeito, deslocamento, conhecimento e tempo, coordenado pelo professor, professor Valdir Barzotto, da Faculdade de Educação da Universidade de São Paulo - FEUSP, que propõe investigar os mecanismos que concorrem na formação de imagens em contextos multilíngues em quatro instâncias argumentadoras: o Estado, a Igreja, a Universidade e a Comunidade. Para este artigo, delimitamo-nos ao âmbito da Universidade, como produtora da imagem do ensino de língua portuguesa para estrangeiros sob suas diversas concepções, que se articula com a nossa experiência enquanto professor de PLE na graduação de Linguística Aplicada à Tradução da Universidade de Santiago de Chile.

Nesse sentido, o artigo se insere, como mencionamos, na "instância universidade", tensionando o ensino de língua portuguesa para falantes de outras línguas, por essa instituição tratar o ensino do PLE por meio de várias terminologias, construindo imagens diversas em determinados contextos que demandam vários focos. Assim, cada contexto gerou uma disciplina referente ao ensino de português, com denominações distintas, que requer ser estudada.

O ensino de português para estrangeiros tem pouca produção científica e didática voltadas para a prática pedagógica, talvez, pela falta de consistência de políticas linguísticas e educacionais direcionadas para a área. Podemos mencionar, das poucas que existem, as iniciativas criadas pelo Instituto Camões (de Portugal) e a dos leitorados do ensino de português no estrangeiro (do Itamaraty, Brasil). Além dessas iniciativas, podemos mencionar 
as poucas universidades que têm uma licenciatura específica em PLE no Brasil. Essas são iniciativas que não recobrem as demandas do ensino do PLE.

As várias denominações/concepções criadas confundem ainda mais o processo de pesquisa a respeito do tema. Ainda que os projetos existam, contudo, faltam pesquisas para avançar na área, principalmente nos cursos de Letras das universidades para que, na formação inicial, o estudante da graduação já se encaminhe para uma nova carreira de pesquisa e de profissão na área do ensino de português para não nativos. Para Almeida Filho (2017), existem iniciativas para o ensino de Português como Segunda Língua e Língua Estrangeira (PL2/PLE) provenientes de ações de algumas universidades ou com apoio da iniciativa de algumas escolas privadas e publicações em escala menor, do apoio oficial governamental por meio dos Ministérios de Relações Exteriores e da Educação, com a implementação do Certificado de Proficiência em Língua Portuguesa para Estrangeiros (Celpe-Bras) para avaliar proficiência.

Nessa perspectiva, as várias denominações para o ensino de português para estrangeiros ofuscam o entendimento dos profissionais inseridos no processo de ensinoaprendizagem da língua portuguesa para estrangeiros. Dentre as várias terminologias, encontramos: Português Língua Estrangeira (PLE); Português Segunda Língua (PL2); Português Língua não Materna (PLnM); Português Língua de Herança (PLH); Português Língua de Acolhimento (PLAc); Português Língua Adicional (PLA); Português para Fins Específicos (PFE), entre outras. Por essa razão, urge discutir a respeito dessas terminologias para melhor clareza ou foco curricular.

Posto isso, é conveniente analisarmos a prática docente e suas percepções sobre esses termos para classificar o ensino da língua portuguesa para estrangeiros, pois, na prática, pressupomos que eles não se justificam, de sorte que seria realizar uma divisão do português que é o mesmo. Consideramos que a diferença está na maneira de abordar e tematizar de modo a atender a demanda do estudante em fase de aquisição do português como língua estrangeira, como uma segunda língua ou como uma língua a mais para se comunicar.

Posto isso, o objetivo principal do artigo é verificar as percepções de ensino de PLE construídas em função das várias terminologias e comprovar em que medidas aquelas construídas na sala de aula, pela atuação do professor, coincidem com o que está preconizado na bibliografia da área. Para alcançarmos esses objetivos, aplicamos questionários a professores que trabalham com o PLE em universidades brasileira e estrangeira.

Com base nos resultados deste estudo, pretendemos provocar uma reflexão teórica e metodológica sobre o lugar do professor de PLE, assim como, diante dessas tendências tão 
marcantes no ensino do PLE e que condicionam o desempenho deles nas aulas, cabe nos questionar: como eles entendem essas diversas nomenclaturas? Qual metodologia usar para cada especificidade? Que material didático utilizam? Essas e outras questões serão analisadas a fim de trazer algum avanço conceitual e metodológico significativos, por entendermos que os resultados desta investigação podem contribuir para a rede ampla de outros trabalhos de pesquisa que se debrucem sobre as temáticas do ensino de PLE.

\section{Fundamentação teórica}

Nesta seção, contextualizamos e apresentamos conceitos de classificações utilizadas para o ensino de Língua Portuguesa para estudantes estrangeiros. Por oposição ao conceito de Português Língua Materna (PLM) ou Língua 1 (L1), surgiu o conceito de português Língua não Materna (PLnM). O conceito PLnM é amplo e abarca os conceitos de Português Língua 2 (PL2) e Português Língua Estrangeira (PLE). Essas terminologias podem tratar tanto de aquisição, como de aprendizagem da língua. Atravessando essas classificações, têm-se o português língua de herança (PLH); o português língua adicional (PLA); o português língua de acolhimento (PLAc); e o português língua para fins especiais (PLFE). São várias terminologias para ensinar o estrangeiro não falante de português ou o estrangeiro que deseja aprofundar seus conhecimentos. Cada um desses termos é tratado separadamente nos parágrafos seguintes.

O Português Língua Materna (PLM) é a língua mãe, aquela falada pelos pais e outros familiares. Em outras palavras, é a língua da comunidade, sendo a primeira língua adquirida pelos indivíduos expostos a ela inicialmente. Nesse contexto, há uma relação afetiva com a língua do cotidiano que predomina na sociedade onde o indivíduo está inserido. De acordo com Maia (2019), esta é também a língua usada pelos professores para ensinarem aos estudantes estrangeiros.

Conforme Altenholfen (2002), a língua materna constitui-se como um conceito dinâmico, por variar de acordo com traços considerados relevantes para o momento em que o falante vivencia, podendo ser a primeira língua que ele aprende ou também quando ele aprende essa L1 concomitantemente com outra língua; ao compartilhar usos e funções específicos, mas com uma língua dominante, identificada pela língua dos pais, que possui um valor afetivo próprio. Na situação de bilinguismo precoce e simultâneo, há a possibilidade de o falante internalizar duas línguas com domínio equivalente entre elas. 
Lemke (2010) concorda com Altenholfen (2002) no tocante à possibilidade de a língua materna ser a L1 ou a L2 quando adquiridas simultaneamente. Isso é possível hoje no Brasil, pois as línguas de imigração são patrimônio cultural e, em alguns lugares do país, a língua do imigrante é divulgada para fins comerciais e turísticos, principalmente no Sul, situação diferente dos tempos em que o estrangeiro não podia usar sua língua materna. Por isso, é possível que os pais estrangeiros usem tanto o português quanto sua língua para conversar com os filhos, que adquirem duas línguas ao mesmo tempo: a portuguesa e a dos pais.

Para Flores (2013), o Português Língua não Materna (PLnM) tem um conceito amplo, incluindo diferentes formas de aquisição, aprendizagem e domínio da Língua Portuguesa, além de se tratar de um conceito próprio do contexto do português de Portugal.

De acordo com Baltazar (2019), o conceito de língua não materna opõe-se ao de língua materna e abrange os conceitos de L2 e Língua Estrangeira (LE), podendo causar muita confusão relacionada aos usos da língua. Nessa perspectiva, o LPnM é o PLE, incluindo todas as denominações dadas ao ensino de português para estrangeiros.

A aquisição de uma segunda língua (L2) não se refere apenas a aprender L2, mas também a terceira, a quarta e assim por diante. No caso do português, a aquisição diz respeito ao PL2. Aprender PL2 acarreta a aquisição de conhecimentos sobre uma nova língua, atribuindo sentidos inteligíveis, ao desenvolver a comunicação necessária para a interação discursiva. Aprende-se o PL2 em contato com esta língua em um contexto de ensinoaprendizagem, por meio de conhecimentos básicos da língua, gramáticas, dicionários, entre outros (MENEZES, 2014).

Contudo, a aquisição de uma L2 e de uma LE é parecida, sendo a primeira inconsciente, já que, na prática, os estudantes possuem habilidades linguísticas de fala, pois dominam capacidade cognitiva e organização do pensamento adquiridas com a L1.

O português como segunda língua apresenta papel ativo e contínuo na formação das identidades dos aprendizes, partindo da concepção de que identidade não é fixa. Sendo assim, a língua, de modo especial a PL2, é constitutiva e constituída pela identidade do aprendiz, de modo que a língua permite à pessoa negociar sua compreensão de si mesma em diferentes lugares e momentos no tempo, ganhando acesso ou não às relações de poder e oportunizando-lhe posicionar-se por meio da fala nas interações sociais (MAIA, 2014, p. 49).

A LE em geral, incluindo o PLE, é aprendida pelo educando e fundamenta-se na cultura do falante que vê na capacidade de se comunicar em uma LE a oportunidade de se 
apropriar de uma das competências essenciais da língua para a realização pessoal (MENEZES, 2014).

O estudante estrangeiro chega em busca de uma formação profissional em um mestrado ou doutorado. Para isso, ele necessita avançar nas práticas sociais de letramento acadêmico e por essa razão deve também avançar no nível de conhecimento da língua (LEURQUIN; OSÓRIO, 2019, p. 60).

Nessa perspectiva, a procura por cursos de PLE pode estar associada a demandas de estudantes estrangeiros que desejam melhorar as práticas sociais, por meio da Língua Portuguesa, e compreender textos para mestrados e doutorados, bem como para outros cursos e finalidades.

Quando se pensa nas denominações PL2 e PLE implica reconhecer um ensino de português para aqueles que possuem uma L1 diferente. Esta situação faz vislumbrar caminhos em meio a uma variedade de terminologias para a formação de professores. A multiplicidade de nomes dados às disciplinas que abordam PL2/PLE se deve ao fato de a Língua Portuguesa ter múltiplos interesses daqueles que buscam aprendê-la.

As necessidades comunicativas dos aprendizes de PLE-PL2 no contexto contemporâneo demandam uma abordagem de ensino-aprendizagem capaz de instigar os estudantes a interagir de maneira eficaz e adequada nos diversos espaços pluriculturais (REIS, 2014, p. 35).

Associar essas duas terminologias permite que o professor atenda às demandas dos estudantes por particularidades contextuais específicas em sua forma de atuar, adequando e complementando, conforme os objetivos que levam o estrangeiro a aprender o português como L2/PLE. O ensino de Língua Portuguesa como língua estrangeira e/ou segunda língua não deveria se resumir em nomenclaturas. Denominações como L2 e PLE poderiam abarcar todas as terminologias.

O importante é o professor considerar que a sala de aula é heterogênea, porque é composta por seres que possuem uma diversidade, mesmo que falem a mesma língua, posto que eles têm crenças, estilos de aprendizagem, demandas, interesses, preferências, metas, motivações e desejos divergentes. Por essa razão, o professor precisa ser sensível às culturas dos educandos na interação durante as aulas, considerando, em suas práticas, a cultura e as diferenças pessoais. É preciso compreender que os estudantes estão em processo de construção e reconstrução de saberes e de identidades, o que requer abertura para as especificidades e demandas que vão surgindo. Devido a isso, os materiais para ensinar PL2- 
PLE precisam estar contextualizados com as necessidades reais desses sujeitos, devendo ser flexíveis, adaptáveis com uma diversidade de temas e gêneros textuais para uma prática que seja significativa para os educandos (REIS, 2014).

O Português Língua Adicional (PLA) foi denominada assim por ela não ser a segunda língua do estudante, pois ele já possui duas ou mais línguas. A terminologia "adicional” se ajusta a esta situação e pode ser uma definição mais apropriada.

Muitas famílias constituídas por mãe e/ou pai (ou, em alguns casos, até mesmo avós) brasileiros, que criam filhos (ou netos) no exterior, vivenciaram situações em que o português foi língua de interação familiar, convivendo com língua(s) local(is) em que as crianças eram, em geral, escolarizadas e que, portanto, caracterizavam o uso do português como língua de herança, mesmo antes da sistematização do uso desse conceito (BRASIL, 2000, p. 47).

Desse modo, a língua adicional diz respeito a uma língua que o estudante resolveu incluir no seu repertório, pois se trata de uma língua que está sendo aprendida e que não é nem primeira e nem segunda. Para ele, esta é uma língua estrangeira que pode ser considerada adicional, porque o estudante precisa ou deseja desenvolver habilidades para se comunicar. Nesse sentido, Dell'Isola (2012, p. 61) afirma que “o termo língua adicional se refere a uma língua que está sendo aprendida/vivenciada pelo indivíduo, de forma positiva, tendo o sujeito como agente da linguagem."

Conforme Maia e Oliveira (2019), a concepção de PLA se embasa nos processos de multiletramentos, interculturalidade que considera a linguagem como discurso, bem como mediadora nas relações socioculturais. Nessa concepção, o PLA se centra na comunicação e construção de conhecimentos, com o desenvolvimento de habilidades multiculturais, considerando a participação do educando por meio da interação.

As Propostas Curriculares para Ensino de Português no Exterior - O Português como Língua de Herança (PLH) -, refere-se a questões migratórias e tem o foco no português brasileiro. Um grande fluxo de brasileiros foi para o exterior nos séculos XX e XXI. Existe estimativa de que há mais de três milhões de brasileiros vivendo no exterior, quase metade deles na América do Norte e um quarto na Europa. As famílias se esforçam para manter a Língua Portuguesa tanto no seio familiar quanto no ambiente escolar (BRASIL, 2020). Esse documento traz propostas para o ensino de PLH, considerando o nível, as habilidades linguísticas de expressão e compreensão oral e escrita, bem como seus componentes específicos. 
O emprego da concepção de língua de herança já existia, mas seu uso correlacionado à Língua Portuguesa é recente, apesar de sua trajetória ser longa.

A partir dos anos de 1990, o uso do português brasileiro e de outros países, em que o idioma é língua oficial, aumentou as situações de interação familiar no exterior, contribuindo, assim, para a necessidade de se compreender o fenômeno na perspectiva linguística específica. A língua de herança tornou-se tema para estudos acadêmicos com vistas a entender a complexidade social e linguística, com propostas e ações para desenvolver e expandir a LPH, iniciando sua trajetória e ampliando-se com rapidez devido à velocidade tecnológica. Isso facilitou a interação entre familiares, professores, membros de associações e grupos que se formaram com objetivos de ensino de português e de aspectos culturais inerentes para crianças nascidas em outros países.

O Português Língua de Acolhimento (PLAc) está associado a fenômenos de mobilidade humana que vêm ocorrendo no Brasil e no Chile, por exemplo. Os países têm recebido muitas pessoas de várias partes do mundo, tais como haitianos e venezuelanos, entre outros. Geralmente, elas vêm em busca de proteção, liberdade e segurança. Esta situação precisa de políticas públicas para que eles vivam com dignidade, como cidadãos em situação de refúgio. Além disso, esses sujeitos que se deslocam de seus países necessitam aprender a língua do local para se comunicar, a língua de acolhimento, no caso, o português. Segundo Barbosa (2016), o PLAc inter-relaciona os conceitos de inserção social, aquisição de língua e comunicação.

[...] a língua de acolhimento tem a função pragmática de prover ensinamentos básicos de uso real para o cotidiano e tem um papel particularmente importante a desempenhar no processo de interação de imigrantes no Brasil, país anfitrião de estudantes imigrados ou refugiados (SANTOS, 2018, p. 23).

O PLAc não se constitui como um desejo ou escolha do estrangeiro. Sua finalidade se encerra no acolhimento em si, pois se ele resolver aprender a língua, aprenderá um português para interagir, trabalhar ou para sua sobrevivência no país.

Segundo Oliveira (2019), estudos sobre PLAc são recentes no Brasil e têm crescido muito desde o início de pedidos de refúgio pelos sírios e haitianos ocorridos no início da década de 2010. Além disso, desde 2017, o país recebe um fluxo bastante significativo de famílias venezuelanas, que atravessam a fronteira ao norte. Eles vêm para fugir da fome e da miséria pela qual passam no país vizinho. 
O Ensino de Línguas para Fins Específicos (ELFE) pode ser definido como ensino instrumental que se aplica ao de língua materna ou estrangeira, para atender a demandas de situação-alvo, cujo ensino se estende ao de línguas em contextos educacionais para natureza específica. Esta estratégia de ensino atende às especificidades do educando e possibilita suprir suas demandas. Desse modo, os estudantes:

[...] passaram a ser respeitados como sujeito principal do processo de ensinoaprendizagem, começam a ser vistos como indivíduos ímpares, cada qual com suas necessidades e interesses, influenciando diretamente em sua motivação de aprender - justifica-se, dessa forma, o surgimento de uma abordagem que tem o foco nas necessidades do aluno como característica principal (LOBO, 2017, p. 74).

O foco no ensino de ELFE está centrado no estudante, ao se voltar para finalidades específicas, e isso pode ser exemplificado com o Programa Mais Médicos, que recrutou médicos de Cuba. Foi preciso trabalhar com eles um português instrumental, para contextualizá-los com o português para fins de realizar consultas e tratamentos em pacientes brasileiros. Nesse caso, eles aprenderam Português Língua para Fins Específicos (PLFE). Isso ocorre também em eventos internacionais realizados no Brasil, onde uma parcela dos participantes busca aprender o português voltado para o campo semântico relativo ao tema abordado.

O ensino de PLFE vem crescendo nos últimos anos e causando o interesse de profissionais estrangeiros das mais diferentes áreas que precisam ler, escrever e interagir para se inserir no mercado de trabalho brasileiro. O PLFE se relaciona a profissões ou carreiras dos estudantes que precisam usar o português em situações de comunicação de trabalho (SOUSA; LACERDA; SILVA, 2014).

\section{Procedimentos metodológicos}

Esta é uma pesquisa com enfoque qualitativo, que tem como objetivo analisar as percepções dos docentes de PLE sob os diferentes conceitos/classificações. Foi realizado um questionário com perguntas abertas e fechadas aplicado a dezoito professores que atuam em PLE. Dez deles são brasileiros, um português, três chilenos, dois argentinos e dois colombianos. Tais professores ensinam PLE em universidades ou institutos, em cursos optativos ou obrigatórios, na Argentina, no Brasil, no Chile e na Colômbia. As idades de 79\% dos entrevistados variaram de 25 a 35 anos; $72 \%$ da população era do sexo feminino. Os dados foram analisados a partir da metodologia de análise de conteúdo. 
$\mathrm{Na}$ elaboração do questionário foram considerados dois aspectos fundamentais: os objetivos do trabalho e as áreas fundamentais que são consideradas no PLE. As respostas dadas pelos respondentes possibilitaram a coleta de alguns dados que, por sua vez, facilitaram o processo inferencial sobre as cinco questões levantadas, suas afirmações foram interpretadas, explicadas e algumas previsões realizadas.

Foi utilizada a ferramenta do Google Forms, que permite a elaboração e preenchimento de questionários online de fácil administração. O questionário foi enviado ao e-mail dos professores nos meses de julho e agosto de 2021. O questionário, segundo Gil (1999, p.128), pode ser definido "como a técnica de investigação composta por um número mais ou menos elevado de questões apresentadas por escrito às pessoas, tendo por objetivo o conhecimento de opiniões, crenças, sentimentos, interesses, expectativas, situações vivenciadas etc."

\section{Análise das respostas fornecidas pelos professores de PLE}

A primeira pergunta do questionário se referia ao contexto principal de atuação no ensino de PLE. Para isso, utilizamos como alternativas as diversas concepções utilizadas para o ensino PLE: Português Língua Adicional (REIS, 2014); Português como Língua de Acolhimento (OLIVEIRA, 2019); Ensino de Línguas para Fins Específicos (LOBO, 2017); e Português como Língua de Herança (BRASIL, 2020), e deixamos uma opção para que o professor preenchesse caso não se encaixasse em nenhuma das opções.

A maioria dos professores com os quais foi realizado a pergunta, com uma porcentagem de 98\%, admitem que ensinam Português para fins específicos. Verificamos que mesmo os professores que trabalham em cursos optativos/opcionais de PLE (Colômbia e Argentina) e professores que trabalham com o português como língua de acolhimento (Brasil) responderam que trabalham com o português para fins específicos.

É de convir que as classificações confundem docentes que desempenham uma prática sem sintonia com o nome dado à disciplina. Por isso, há a necessidade de se pensar em um português não estrangeiro, sendo uma língua a mais em aquisição. Nesse particular, talvez fosse "mais prático" encontrar uma única terminologia que abranja as necessidades dos estudantes. Uma das hipóteses que pode gerar tantas denominações talvez esteja relacionada à interculturalidade no ensino de PLE, evidenciando a necessidade de enfatizar algum tipo de demanda que inclui o compartilhamento de culturas, visto que o ensino de língua está associado aos usos socioculturais da língua. 
A segunda questão do questionário tinha como objetivo saber se os professores conhecem as diversas nomenclaturas usadas para denominar o PLE. Para essa questão 70\% dos professores disseram não e $30 \%$, sim. As diferentes correntes linguísticas e metodológicas pelas quais vem passando o PLE ilustram que atualmente não existe uma única corrente que domine o PLE, como podemos vislumbrar os conceitos que apresentamos na fundamentação teórica. Tal como em outras áreas do conhecimento e especialmente no ensino de línguas estrangeiras, verifica-se um grau de aceitação quase majoritário em termos da adoção de várias abordagens e delas retirar o que melhor se ajusta e se adapta às condições particulares do processo de ensino -aprendizagem. No entanto, o que se depreende, quando das respostas para a pergunta é que a maioria do professorado desconhece os conceitos considerados basilares para o PLE.

Assistimos a uma ascensão do PLE nos últimos anos, devido a vários fatores, entre outros, ao interesse de países como a Argentina e o Uruguai para integrá-lo em seus sistemas educacionais. Diante desse panorama, no campo do ensino de PLE, os responsáveis por programas de formação de professores procuram incluir em seus currículos novos percursos formativos que incorporem os avanços obtidos ao longo destes anos na investigação didática e no mundo do PLE, especificamente.

A terceira questão tinha como objetivo saber se os professores de PLE tinham formação em Letras, em outra licenciatura ou em nenhuma. Dos 18 professores que responderam ao questionário, apenas 2 têm licenciatura específica para o ensino do PLE, 10 são formados em Letras para o ensino de PLM, 6 não têm formação em Letras. Essa questão vem comprovar o baixo número de licenciaturas no Brasil para formar professores de PLE. Coelho (2017) indica que apenas a Universidade de Brasília (UnB), que oferece a habilitação em Português do Brasil como Segunda Língua - Licenciatura, que é voltada para estudantes interessados pelo ensino da língua portuguesa para falantes de outras línguas, seja língua estrangeira, língua indígena ou língua de sinais. Cita também a Universidade Federal da Bahia (UFBA), que oferece o curso de Letras Vernáculas e Língua Estrangeira Moderna ou Português como Língua Estrangeira e a Universidade Federal da Integração LatinoAmericana (UNILA), com o curso de licenciatura em Letras - Espanhol e Português como Línguas Estrangeiras, bem como a Universidade Estadual de Campinas que tem a Licenciatura em Letras - Português como Segunda Língua/ Língua Estrangeira, em fase de implementação (dados de 2017), além das licenciadas relacionadas, há de mencionar as atividades formativas que são oferecidas em programas de pós-graduação de diversas 
instituições de ensino pelo país, e muitas são o ponto de partida das pesquisas em PLE desenvolvidas nos cursos de mestrado e doutorado.

$\mathrm{Na}$ Colômbia e no Chile não há licenciaturas de formação de professores de PLE (ANDRADE-STANZANI, 2021; BEZERRA FERREIRA, 2021), na Argentina há as universidades e os institutos superiores, como a Universidad Nacional de Córdoba, a Universidad Nacional de Cuyo, o Instituto de Enseñanza Superior en Lenguas Vivas "Juan Ramón Fernándéz e a Escuela Normal Superior en Lenguas Vivas Sofía Esther Broquen de Spangenberg com os "Profesorado de Portugués".

Depreende-se que no que se refere à formação de professores para atuar em PLE é escassa, considerando as especificidades da área, a questão permanece muito incipiente sobre a questão das graduações existentes, o que pode caracterizar um professor despreparado para atuar no PLE. Identificamos que a ausência de uma formação específica pelos docentes suscita inseguranças na prática docente de dois aspectos: o pedagógico (como ensinar?) e outro disciplinar (o que ensinar?). Os docentes se sentem inseguros por não saber como ensinar PLE. Há reconhecimento da necessidade de um saber pedagógico que oriente e situe o ensino de PLE. Nesse sentido, é necessário refletir sobre o fazer pedagógico baseado em diálogos entre teoria e prática sobre os diversos conceitos existentes de PLE no processo de formação.

$\mathrm{Na}$ quarta questão, perguntamos que material didático o profess or de PLE utiliza em suas aulas. Para a questão acima, 95\% responderam que utilizam como material didático para ensino de PLE gramáticas, livros didáticos de PLE e de PLM e que também preparam o próprio material. Depreende-se dessa resposta duas indagações: por um lado, que os professores são dinâmicos e trabalham com vários tipos de materiais didáticos a fim de ter uma aula diversificada, o que é uma qualidade docente; por outro lado, que o docente não tem um norte sobre qual material didático utilizar e acaba por utilizar todos os que estejam a sua disposição. Considerando que no processo de ensino-aprendizagem de PLE (e de qualquer área), os materiais didáticos são um elemento essencial, entendemos que os escolhidos são alternativas para o desenvolvimento desse processo. Logo, espera-se que esses materiais favoreçam o desenvolvimento das habilidades comunicativas do discente, entendidas como a integração das cinco competências: linguística, sociolinguística, discursiva, cultural etc.

Diante dessa questão, depreendemos que as dificuldades relatadas por $91 \%$ dos inquiridos foi a baixa formação para o ensino de PLE e, como consequência, a escolha do material didático "mais adequado" que atenda a demanda da especificidade de português 
para estrangeiros. Expressões como "não tive preparação" ou "fico muito desorientado" mostram essa situação. Outra questão diz respeito a falta de conhecimento da gramática, que se tornou um grande obstáculo: "Muitas vezes não consegui dar explicações gramaticais. Na universidade trabalha-se muito a pragmática, a análise do discurso, mas a morfossintaxe está em 'desuso' e isso é muito sério para um professor de PLE. Os alunos querem uma boa explicação gramatical. Não é suficiente dizer-lhes 'isso não é dito assim', mas por quê. Acho que os programas devem ser fortes em gramática". Dessa questão, inferimos porque a maioria dos professores optam por usar a gramática como material didático principal para o ensino do PLE, mesmo que muitos relataram que não tenham segurança da metodologia mais adequada, bem como alguns relatam que não sabem explicar adequadamente os elementos da gramática do português, especialmente as estruturas mais complexas.

A quinta questão perguntava se o professor considerava que utilizava metodologia específica para o ensino de PLE. Essa pergunta evidenciou que $80 \%$ dos professores não utilizam metodologias diferenciadas para o ensino de PLE. De acordo com o resultado, inferimos que os docentes não fazem diferença entre ensinar língua materna e ensinar língua estrangeira, no caso, a língua portuguesa. As metodologias de ensino de línguas estrangeiras evoluíram ao longo da história, principalmente a partir de teorias linguísticas, que refletem nas práticas pedagógicas e nos currículos de ensino de línguas. Portanto, é importante que professores, "desenhadores" de currículos conheçam os conceitos que fundamentam o ensino e a aprendizagem de uma língua. É necessário que o professor tenha conhecimento pedagógico para determinar qual a metodologia mais adequada, mas também para refletir sobre a adequação das metodologias, no currículo de PLE.

Nesse sentido, levanta-se ainda a necessidade de uma postura crítica em relação ao papel do ensino de línguas, quando apenas $20 \%$ dos professores disseram que diferenciam as metodologias no ensino de PLE e PLM. Isso vem comprovar que os professores foram formados para ensinar português língua materna, sem formação específica em PLE, o que denota uma necessidade de uma mudança nos currículos de formação de professor de português, mesmo que seja para língua materna, mas que haja disciplinas que foquem em PLE nos currículos dos cursos de Letras. 


\section{Considerações finais}

A análise do questionário revela que os docentes que ensinam PLE em quatro países (Argentina, Brasil, Chile e Colômbia) são, em sua maioria, composta por professores formados não só em Letras e que têm um perfil semelhante, com percepções comuns ao ensinarem PLE sob as diferentes concepções. Dessas percepções, podemos apontar:

- Professores que não têm conhecimento teórico suficiente sobre as várias concepções que existem acerca do ensino PLE;

- A necessidade de criação de mais licenciaturas em Letras para formar professores de PLE ou, ao menos, a reformulação curriculares dos cursos de letras com inserções de disciplinas voltadas para as especificidades do PLE;

- O ensino de português para estrangeiros tem pouca produção científica e didática voltadas para a prática pedagógica, talvez, pela falta de consistência de políticas linguísticas e educacionais direcionadas para a área;

- Nem sempre existe justificativa para o uso de várias classificações para o ensino de português para falantes de outras línguas, pois, muitas vezes, os conceitos se confundem e acabam na prática tendo a mesma abordagem pedagógica;

- A necessidade de oferecer aos professores espaços para formação continuada e reflexão com seus pares acadêmicos;

- O professor não pode se prender a uma das terminologias;

- A título de provocação, seria o caso de tirar o caráter de língua estrangeira?

Nessa perspectiva, as respostas dos docentes constituem um apelo à reflexão sobre o ensino de PLE que estão oferecendo aos alunos na universidade, seja em cursos optativos ou obrigatórios. Este trabalho nos leva a pensar na possibilidade de "desestrangeirizar" mais o ensino de PLE, o que nos leva a entender que os muitos termos para conceitualizar o PLE, na prática, nem sempre se justificam, pois seria realizar uma divisão do português que é o mesmo. A diferença está, possivelmente, na maneira de abordar e tematizar de modo a atender a demanda do estudante em fase de aquisição de português como língua estrangeira, como uma segunda língua ou como uma língua a mais para se comunicar.

Esperamos, como resultado parcial, ter encontrado esclarecimento para a real necessidade de as universidades criarem várias terminologias, o que dificulta o entendimento sobre a existência ou não de equivalência entre elas. Acreditamos que haverá um avanço conceitual e metodológico significativo, pois este estudo trará contribuições a outros pesquisadores que se debruçam sobre as temáticas do ensino de PLE. 
AGRADECIMENTOS: Ao Dr. Valdir Barzzoto, da USP, pela acolhida e supervisão no pós-doutoramento. À Dra. Cristina Moyano Barahona, Decana da Faculdade de Humanidades da USACH, pela liberação para realização do pós-doutoramento. Ao Prof. Edinson Muñoz, ex-diretor do Departamento de Linguística e Literatura da USACH, pelo apoio à liberação para o pós-doutoramento na USP.

\section{REFERÊNCIAS}

ALTENHOFEN, C. V. O conceito de língua materna e suas implicações para o bilinguismo (em alemão e português). Martius-Staden-Jahrbuch, São Paulo, n. 49, p. 141-161, 2002.

ANDRADE-STANZANI, L. Identidade profissional e formação de professores de português como língua adicional na Colômbia. Íkala, Revista de Lenguaje y Cultura. Medellín, v. 26, n. 2, p. 303-316, maio/ago. 2021.

BALTAZAR, A. M. F. As perguntas em português língua não materna: aprendizagem e ensino. Revista Versalete, Curitiba, SP. v. 7, n. 13, jul./dez. 2019.

BARBOSA, J. B.; FREIRE, D. J. A diversidade linguística no ensino de português como língua adicional e língua estrangeira. Estudos Linguísticos, v. 49, n. 2, p. 651-673, 2020.

BARBOSA, L. M. A. Culturas e imaginários. deslocamentos, interações e superposições. In: COLÓQUIO INTERNACIONAL DA REDE PICNAB, 2., 2016, Brasília. Anais [...]. Brasília, 26 abr. 2016. Disponível em https://www.facebook.com/neppeunb/videos/vb.147509432101038/ 519628491555795 / ?type $=2 \&$ theater. Acesso em: 22 out. 2020.

BARZOTTO, V. H. Modalizações em torno da prática e cristalização da imagem do professor de Língua Portuguesa. In: SOUSA, PAULINO, A. (org.); BARZOTTO, V. H. (org.); SARNPAIO, M. L. P. (org.) Formação de professor de língua portuguesa: quando a linguagem e o ensino se encontram. São Paulo: Paulistana, 2010.

BRASIL. Secretaria de Educação Básica e Conselho Nacional de Educação. Base nacional comum curricular. Brasília: CNE, 2017.

BRASIL. Ministério das Relações Exteriores Secretaria de Comunicação e Cultura. Proposta curricular para o ensino de português como língua de herança. Brasília: FUNAG, 2020.

CARREIRA, M. H. A. Modalização axiológica e configurações linguísticas e textuais: o ponto de vista da proxémica verbal. In: CONGRESSO INTERNACIONAL DA ABRALIN, 2009, João Pessoa. Anais [...] João Pessoa, 2009.

DELL'ISOLA, R. L. P. "Perspectivas teóricas subjacentes às noções de gêneros: textuais ou discursivos?” In: DELL'ISOLA, R. L. P. (org.).Gêneros textuais: o que há por trás do espelho?. Belo Horizonte, MG: FALE/UFMG, 2012. p. 8-19. Disponível em: https://oportuguesdobrasil.files.wordpress.com/2015/02/generos-textuais-o-que-ha-por-trasdo-espelho.pdf. Acesso em: 16 ago. 2021. 
FERREIRA. J. G. B. Mapeamento do ensino do português na educação superior no Mercosul. Da Investigação às Práticas, v. 11, n. 1, p. 150 - 170, 2021.

FILHO, J. C. P. A. O Ensino de português como língua não materna: concepções e contextos de ensino. São Paulo: Museu da Língua Portuguesa, 2017. Disponível em: www.estacaodaluz.org.br. Acesso em: 28 out. 2020.

FLORES, C. Português língua não materna: discutindo conceitos de uma perspetiva linguística. Lisboa: Lidel, 2013. p. 35-46

LEMKE, C. K. Políticas linguísticas: um estudo sobre o ensino de língua espanhola em um contexto multilíngue no Paraná - Brasil. São Paulo: USP, 2010.

LOBO, M. L. S. O ensino de português pra fins específicos no programa mais médicos para o Brasil. 2017. (Tese de Doutorado em Letras) - Universidade de São Paulo, São Paulo, 2017.

MAIA, F. P. S. Atitudes linguísticas em foco: Reflexões em torno das línguas na UNILA. In: MAIA, F. P. S.; MENDES, R. M. G. (org.). Ensino e aprendizagem de línguas adicionais em foco. New Jersey: Boavista Press, 2019.

MAIA, F. P. S.; OLIVEIRA, S. B. Escrita acadêmica em aulas de português como língua adicional na graduação na perspectiva dos multiletramentos. In: OSÓRIO, P.; GONÇALVES, L. (org.). O Ensino do Português como língua não materna: metodologias, estratégias e abordagens de sucesso. Rio de Janeiro: Dialogarts, 2019. v. 2.

MAIA, M. A. G. S. A cultura de aprender português como segunda língua de alunos hispanofalantes do ensino fundamental II em contexto militar de ensino. 2014. Dissertação (Mestrado) - Universidade de Brasília, Brasília, 2014.

MENEZES, L. J. Português como língua estrangeira e segunda língua em Moçambique. PERcursos Linguísticos, v. 4, n. 8, p. 111-129, 2014.

OLIVEIRA, M. Ensino de Português como língua de acolhimento no interior do Rio Grande do Norte: Projeto SOS Português \& Aldeias Infantis. Interfaces-Revista de Extensão da UFMG, v. 7, n. 1, 2019.

PINTO, N. C. O. O ensino de PLE no Brasil: história, formação e conceitos. São Paulo: Universidade São Judas Tadeu, 2014.

REIS, L. M. Através do espelho: o portal do professor de português língua estrangeira/língua não materna (PPPLE) sob uma ótica pluricêntrica e intercultural. Salvador: UFBA, 2014.

SANTOS, E. B. Português língua de acolhimento: interação e inserção social de imigrantes por meio do WhatsApp. 2018. Dissertação (Mestrado em Linguística Aplicada) - Universidade de Brasília, Brasília, 2018.

SILVA, A. O. A formação do professor de português como língua estrangeira: uma proposta. Revista Philologus, Rio de Janeiro, v. 24, n. 72, set./dez. 2018. 
SOUSA, M. A.; LACERDA, N. A.; SILVA, M. T. M. O ensino-aprendizagem de português para fins específicos em cursos de graduação da UFPI. Teresina: UFPI, 2014.

\section{Como referenciar este artigo}

FERREIRA, J. G. B. O ensino de língua portuguesa para estrangeiros: implicações da pluralidade de conceitos. Rev. EntreLínguas, Araraquara, v. 7, n. esp. 6, e021143, dez. 2021. e-ISSN: 2447-3529. DOI: https://doi.org/10.29051/el.v7iesp.6.15423

Submetido em: $29 / 08 / 2021$

Revisões requeridas em: 15/10/2021

Aprovado em: $25 / 11 / 2021$

Publicado em: 28/12/2021 